\title{
Potential of Natural Killer Cell Enriched Conditioned Media for Skin Care and Anti-Aging
}

\author{
Dong Soo Kim, Dong Ju Kim, Hyun Pyo Kim, Sung Hwan Hwang, Jung Hwa Kang* \\ Research \& Development, IMMUNISBIO CO. Ltd., B2, International ST. Mary’s Hospital MTP Mall, Seo-gu, Incheon, Korea \\ Email: *kjunghwa@immunisbio.com
}

How to cite this paper: Kim, D.S., Kim, D.J., Kim, H.P., Hwang, S.H. and Kang, J.H. (2021) Potential of Natural Killer Cell Enriched Conditioned Media for Skin Care and Anti-Aging. Journal of Cosmetics, Dermatological Sciences and Applications, 11, 123-139.

https://doi.org/10.4236/jcdsa.2021.112013

Received: April 28, 2021

Accepted: June 5, 2021

Published: June 8, 2021

Copyright $\odot 2021$ by author(s) and Scientific Research Publishing Inc. This work is licensed under the Creative Commons Attribution International License (CC BY 4.0).

http://creativecommons.org/licenses/by/4.0/

\begin{abstract}
Natural killer (NK) cell is a type of immune cell and is known to be particularly responsible for innate immunity such as anti-cancer immunity, defense mechanisms against infections, and secretion of various cytokines and chemokines for increasing recruitment of other immune cells. In this study, we investigated the potentials of NK-enriched lymphocytes (NKEL) conditioned media (CM) on skin care for cosmeceutical compositions. Various cytokines of NKEL CM can improve wound healing through epithelial-mesenchymal transition (EMT) by increasing KLKs (kallikreins) and reduce metalloproteinase (MMP)-1 and MMP-2 to inhibit wrinkle formation. Our results suggest that NKEL CM which has various cytokines promotes up-regulation of cell migration and KLKs and down-regulation of MMP-1 and MMP-2 by stimulating HaCaT keratinocytes migration. Therefore, NKEL CM can be used as a cosmetic composition that can play a role in skin regeneration and anti-aging.
\end{abstract}

\section{Keywords}

Natural Killer Cell, NKEL, Skin Care, Wound Healing, Anti-Aging, KLKs, MMPs, EMT, Conditioned Media

\section{Introduction}

With the improvement of living standards and the increased demand for beauty, interest in skin beauty is increasing day by day [1] [2]. In response to these demands, researchers are working on finding new, more effective, bioactive, and biocompatible anti-aging compounds in the pharmaceutical and cosmeceutical field [3]. Among them, methods to cope with the aging of the human body are 
being sought. The aging phenomenon is an inevitable process that occurs when the growth and development of the body stops, and it means changes in body composition and function of each organ [4].

The skin is the outermost organ in the body and has the main function of physically and chemically protecting the body, which includes protection from the outside, prevention of moisture loss, and retention of moisture [5] [6]. All of these functions are performed by the stratum corneum [6]. The skin is simply composed of the epidermis and the dermis from the outermost. Among them, the epidermis, which is directly exposed to the external environment, is mainly composed of keratinocytes and is only about $0.05-1.5 \mathrm{~mm}$. Keratinocytes continue to divide and differentiate, move to the granular layer and stratum corneum, create intracellular lipid, and form a protective film [7] [8]. Keratinocytes formed in the stratum corneum are eliminated by various protein enzymes, and in this process, various proteins and lipids are produced [8]. As aging progresses, skin cells gradually lose their function [9]. Keratinocytes produce keratin at the outermost part of the skin through the final differentiation stage and maintain the skin protective function [10]. However, if dead skin cells accumulate in the skin due to the slowing of skin turnover due to aging, it can cause fine wrinkles and lower immune function [11]. Therefore, proper exfoliation can also be important in preventing skin aging.

KLKs encoded by the largest contiguous cluster of protease genes in the human genome are secreted serine proteases with various physiological roles [12]. The KLK protease is now known to be involved in mechanistic pathways that regulate skin desquamation, tooth enamel formation, kidney function, seminal liquefaction, synaptic neural plasticity, and brain function [13]. One of the most intensively studied organs for KLK function is the skin [14]. The most well-known role of KLKs in the skin is related to the detachment of keratinocytes from the stratum corneum. In particular, it is known that KLK5 and KLK7 are highly associated with desquamation [15]. KLKs operate as proteolytic cascades and, in the skin, KLK5 is believed to be the main activator of the cascade. KLK5 can be autoactivated, and its activity is restricted from deeper stratum corneum to stratum granulosum. When activated, KLK5 converts both proKLK6 and proKLK14 to active forms through proteolytic cleavage [16].

MMPs are proteinases closely related to ECM remodeling [17]. Their family can not only degrade all kinds of ECM proteins but also process a number of bioactive molecules [18]. ECM is degraded by various proteinases, of which MMP-1 is known to be mainly involved in collagen turnover [19]. MMPs are enzymes that play an important role in various destructive processes, including inflammation, tumor invasion, and skin aging [20]. Up-regulation of MMPs in the dermal fibroblast induces the degradation of collagen and other ECM proteins [21]. MMP-1 primarily degrades Type I and II collagens and is closely related to skin aging because it secondarily degrades collagen primarily decomposed by gelatinases MMP-2 and MMP-9 [22]. Therefore, the association of aging can be 
seen through the measurement of MMP concentration or expression.

NK cells are a type of immune cell and are known to be particularly responsible for innate immunity [23]. NK cells are responsible for not only anti-cancer immunity but also defense mechanisms against infections such as viruses and bacteria by receptor-ligand interaction without stimulation of specific antigens [24]. The cytotoxicity of NK cell and various cytokines and chemokines secreted by the cells play a role in the elimination of infected cells by increasing the recruitment of other immune cells [25].

The regulation of skin desquamation and anti-wrinkle is associated with changes in various conditions.

In this study, the cosmeceutical effect of NKEL CM was confirmed by analyzing the roles in HaCaT keratinocytes. When an imbalance occurs in the formation and dropout of dead skin cells, it can adversely affect not only the aging of the skin but also the cosmetic aspects. The NKEL CM secretes various cytokines in addition to direct immune activity, so the effect of this on the viability of HaCaT keratinocytes was evaluated. Additionally, the effect on cell migration was verified through NKEL CM treatment and the alteration of E-cadherin, an EMT marker, was observed.

And, it was confirmed whether these changes were due to either KLK or MMP closely related to skin health and aging.

\section{Materials and Methods}

\subsection{Materials}

Dulbecco's modified Eagle's medium (DMEM), Penicillin-streptomycin solution, and fetal bovine serum (FBS) were purchased from Gibco (Life technologies Korea, Seoul, Korea). 3-(4,5-dimethylthiazolyl-2)-2,5-diphenyltetrazolium bromide (MTT), bicinchoninic acid (BCA) solution, fluorescein isothiocyanate (FITC)-conjugated secondary antibody, sodium dodecyl sulfate (SDS), Dimethyl sulfoxide (DMSO) was obtained through Sigma-Aldrich (St. Louis, MO, USA). Glyceraldehyde 3-phosphate dehydrogenase (GAPDH) was obtained from Santa-Curz Biotechnology (Santa Cruz, CA, USA). E-cadherin, MMP-1, and MMP-2 antibodies were obtained through Cell Signaling Technology (Danvers, MA, USA). Enhanced chemiluminescence (ECL) reagents were obtained through GE Healthcare BIO-Sciences (Piscataway, NJ, USA). NK sol (IMMUNISBIO. Co. Ltd., Incheon, Korea).

\subsection{Cell Culture}

HaCaT cells (ATCC 12192), spontaneously immortalized human keratinocyte line was cultured in DMEM (full medium) supplemented with $10 \%$ (v/v) FBS, $100 \mathrm{~m} / \mathrm{L}$ penicillin, and $100 \mu \mathrm{g} / \mathrm{mL}$ streptomycin at $37^{\circ} \mathrm{C}$ and $5 \% \mathrm{CO}_{2}$. Additionally, cells were cultured with 1\% FBS DMEM 24 hours before treatment with conditioned media. 


\subsection{NK Cells Isolated PBMC and Conditioned Media Preparation}

PBMCs isolated from blood were washed with normal saline, and the cell suspension was centrifuged at $400 \mathrm{~g}$ for $10 \mathrm{~min}$. The obtained cells were cultured for 2 days at $37^{\circ} \mathrm{C}$ and $5 \% \mathrm{CO}_{2}$ in $\mathrm{KBM} 502$ media containing NK sol (IMMUNISBIO. Co. Ltd.) with $2.0 \times 10^{7}$ cells/flask. After this, subculture was performed at intervals of 2 - 3 days. After culturing for 14 days, NK cells were centrifuged at $400 \mathrm{~g}$ to remove the cells, and the supernatant was obtained to obtain NKEL CM.

\subsection{Flow Cytometry}

For NK cell staining, cells were harvested and washed, centrifuged at $350 \mathrm{~g}$ for 5 min, and resuspended in ice-cold FACS buffer. Flow-cytometric analysis of surface expression of CD3, CD16, CD56 molecules was performed after $30 \mathrm{~min}$ incubation at $4^{\circ} \mathrm{C}$ in presence of saturating concentrations of antibodies. Wash and staining cells were analyzed FACS analysis for NK portion by BD Accuri ${ }^{\mathrm{TM}}$ C6 Plus.

\subsection{Cytokine Array}

The conditioned media obtained from NK cell culture were analyzed according to Raybiotech's kit manual. Briefly, each membrane was blocked at room temperature and reacted overnight at $4^{\circ} \mathrm{C}$ with the sample and Human Cytokine Array Detection Antibody Cocktail. After washing, it was reacted with Streptavidin-HRP solution at room temperature for $30 \mathrm{~min}$. Then, the membrane was reacted with a Chemi Reagent mix, and the spot was analyzed using $\mathrm{Da}$ vinch-chemidoc (Davinch-K, Seoul, Korea).

\subsection{Cell Proliferation Assay}

$\mathrm{HaCaT}$ cells were cultured in a full medium for 24 hours in 96-well plates at 8.0 $\times 10^{3}$ cells/well. After that, cells were incubated for 24 hours in 1\% FBS DMEM. Then, the cells were treated with various concentrations of NKEL CM based on 1\% FBS DMEM and cultured for 24 hours, followed by MTT assay to measure the viability of the cells. Briefly, $10 \mu \mathrm{L}$ of MTT solution $(5 \mathrm{mg} / \mathrm{mL}$ in phosphate-buffered saline) was treated in each well of a 96-well plate and incubated for 4 hours at $37^{\circ} \mathrm{C}$. The formed formazan was dissolved in $200 \mu \mathrm{L}$ of DMSO and absorbance was measured at $560 \mathrm{~nm}$.

\subsection{Scratch Cell Migration Assay}

A scratch cell migration assay was performed to measure the migration of $\mathrm{Ha}$ CaT keratinocytes by NKEL CM. For the in vitro cell migration assay, the method summarized by Calvin R. Justus, Nancy Leffler, Maria Ruiz-Echevarria, and $\mathrm{Li} \mathrm{V.} \mathrm{Yang} \mathrm{was} \mathrm{referenced} \mathrm{[26].} \mathrm{Cells} \mathrm{were} \mathrm{treated} \mathrm{with} \mathrm{various} \mathrm{concentrations} \mathrm{of}$ NKEL CM based on 1\% FBS DMEM and cultured for 24 hours, resulting in a confluence of $95 \%$ to $100 \%$. A straight scratch was made with a $200 \mu \mathrm{L}$ plastic pipetted tip and washed with PBS to remove cell debris. Then, HaCaT keratino- 
cytes were cultured in fresh media. The picture data were photographed using an Olympus CKX41 microscope and an IMT cam 3 digital camera (Olympus Corp, Tokyo, Japan) after 24 hours. The cell migration rate was measured using ImageJ software, and the area reduction rate of the cell-free area was calculated.

\subsection{Western Blot}

Whole cell lysate is a radioimmunoprecipitation assay (RIPA) lysis buffer containing protease/phosphatase inhibitor cocktail (150 mM NaCl, $1 \%$ Triton $\mathrm{X}-100,0.5 \%$ sodium deoxycholate, $0.1 \%$ SDS, $50 \mathrm{mM}$ Tris $\mathrm{HCl}, \mathrm{pH} 8.0$ ). After that, the protein concentration was measured using a BCA reagent. Briefly, media protein or lysate protein was separated by $10 \%$ SDS-polyacrylamide gel electrophoresis (SDS-PAGE) gel and transferred to a polyvinylidene fluoride membrane. Protein transferred membrane was treated with 5\% skim milk (in Tris-buffered saline containing $0.1 \%$ Tween-20) to block non-specific binding. The blocked membrane was reacted overnight at $4{ }^{\circ} \mathrm{C}$ with the primary antibody diluted with $5 \%$ skim milk of an appropriate concentration. Then, the horseradish peroxidase-conjugated secondary antibody was reacted at room temperature for 2 hours and detected using an ECL reagent. The detected band was quantified densitometrically through ImageJ software.

\subsection{Immunofluorescence Staining of E-Cadherin}

$\mathrm{HaCaT}$ cells were cultured at $95 \%$ to $100 \%$ confluence on glass coverslips in a 6 well-plate. After 24 hours of treatment with various concentrations of NKEL CM in 1\% FBS DMEM, linear scratches were applied to the cell monolayer using a $200 \mu \mathrm{L}$ plastic pipette tip. Washed with PBS and incubated for 24 hours in fresh media. The cells of the cover glass were washed with ice-cold PBS and fixed ( $\mathrm{pH}$ 7.4) for 10 minutes with $4 \%$ paraformaldehyde. Then, it was incubated for 30 min with $1 \%$ bovine serum albumin in PBS with $0.1 \%$ tween 20 . The reaction was carried out at $4^{\circ} \mathrm{C}$ for 12 hours using E-cadherin antibody, and at room temperature using FITC-conjugated secondary antibody for 2 hours. FITC fluorescence images were obtained using a LEICA DMi8 fluorescence microscope (Leica Microsystems, Wetzlar, Germany).

\subsection{Statistical Analysis}

Statistical analyses were performed using the student's t-test. A p-value $<0.05$ was considered significant for all tests. The results were expressed as the means \pm standard deviations. All experiments were performed at least in triplicate.

\section{Results}

\subsection{NK Cell and CM Analysis}

PBMCs isolated from the blood of a healthy donor were cultured with treated NK sol in KBM502 for 14 days, and the phenotype of the cultured cells was analyzed. NK cells can be identified by the presence of CD16, CD56, and the ab- 
sence of CD3 (CD3- CD16+ CD56+). T cells express CD3 (CD3+) and NKT cells express CD3, CD16, and CD56 that share the function and phenotypes of NK and T cells (CD3+ CD16+ CD56+). The proportion of lymphocytes before and after culture is shown in Figure 1. The proportion of NKT, T, and NK cells in PBMCs before culture were $10.0 \%, 51.0 \%$, and $24.8 \%$, respectively (Figure $1(a))$. In order to confirm the effect of NK sol, PBMCs were cultured with and without NK sol, and the proportion of cells was investigated. The proportion of NK cells did not increase in the absence of NK sol (Figure 1(b)), but increased to $97.1 \%$ in the presence of NK sol (Figure $1(\mathrm{c})$ ). It was confirmed through cytokine array that MIP-1 $\alpha / \beta$, CCL5 (RANTES), GM-CSF, IFN- $\gamma$, IL-5, IL-8, IL-13, and MIF significantly increased (Figure 2).

\subsection{The Effect of NKEL CM on the Viability of HaCaT Keratinocytes}

We performed MTT assay to confirm the effect of NKEL CM on the viability of $\mathrm{HaCaT}$ cells. When the culture of PBMC treated with NK sol is completed, more than $90 \%$ of NK cells were obtained, and the culture medium was treated with $\mathrm{HaCaT}$ keratinocytes at a concentration of $0.5 \%$ to $20 \%$. The number of $\mathrm{HaCaT}$ keratinocytes treated with NKEL CM decreased slightly at the concentration of $20 \%(93.07 \% \pm 11.89 \%, \mathrm{p}<0.01)$, but there was no change in viability at concentrations below that (Figure 3). These results show that NKEL CM has no significant cytotoxicity in keratinocytes.

(a)

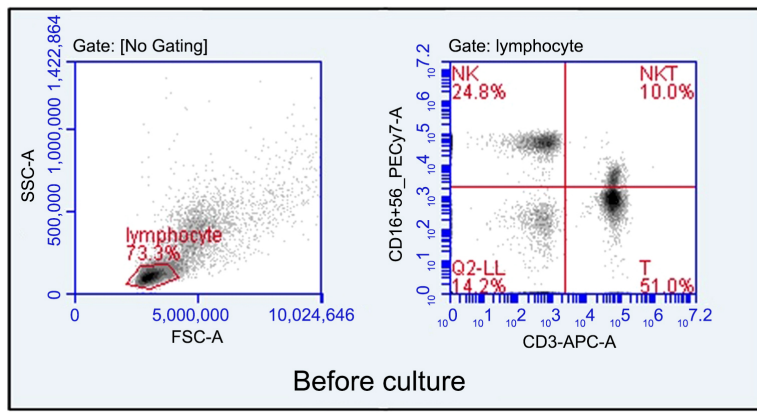

(b)
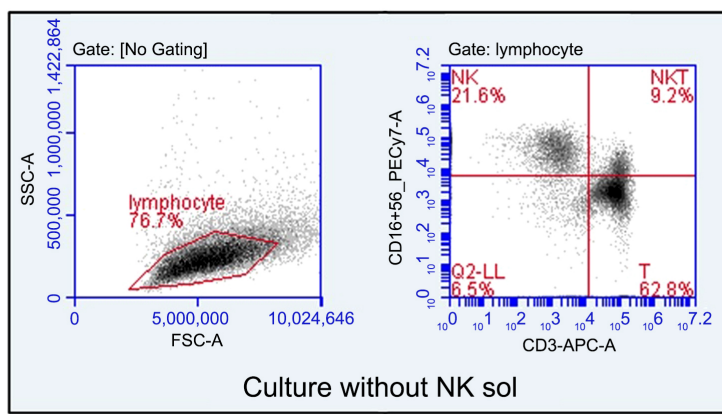

Culture without NK sol

(c)
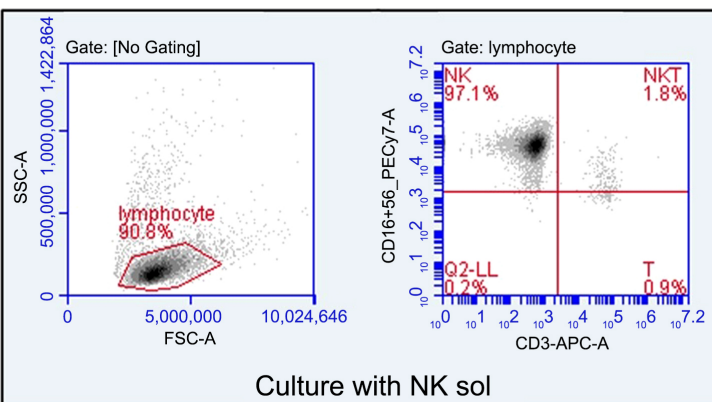

Figure 1. Flow cytometry of CD3-CD16+CD56+ NK cells that were cultured with NK sol in KBM502 medium. After 14 days, cultured cells were analyzed by BD Accuri ${ }^{\mathrm{TM}}$ C6 Plus. (a) Portion of NKT, T, and NK cells in lymphocytes before culture. (b) Portion of NKT, T, and NK cells in lymphocytes after 14 days of culture without NK sol in KBM502. (c) Portion of NKT, T, and NK cells in lymphocytes after 14 days of culture treated with NK sol in KBM502. 
(a)

Con

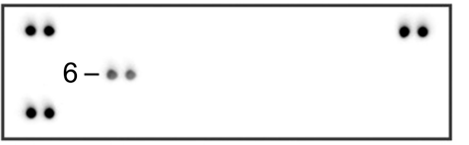

(b)

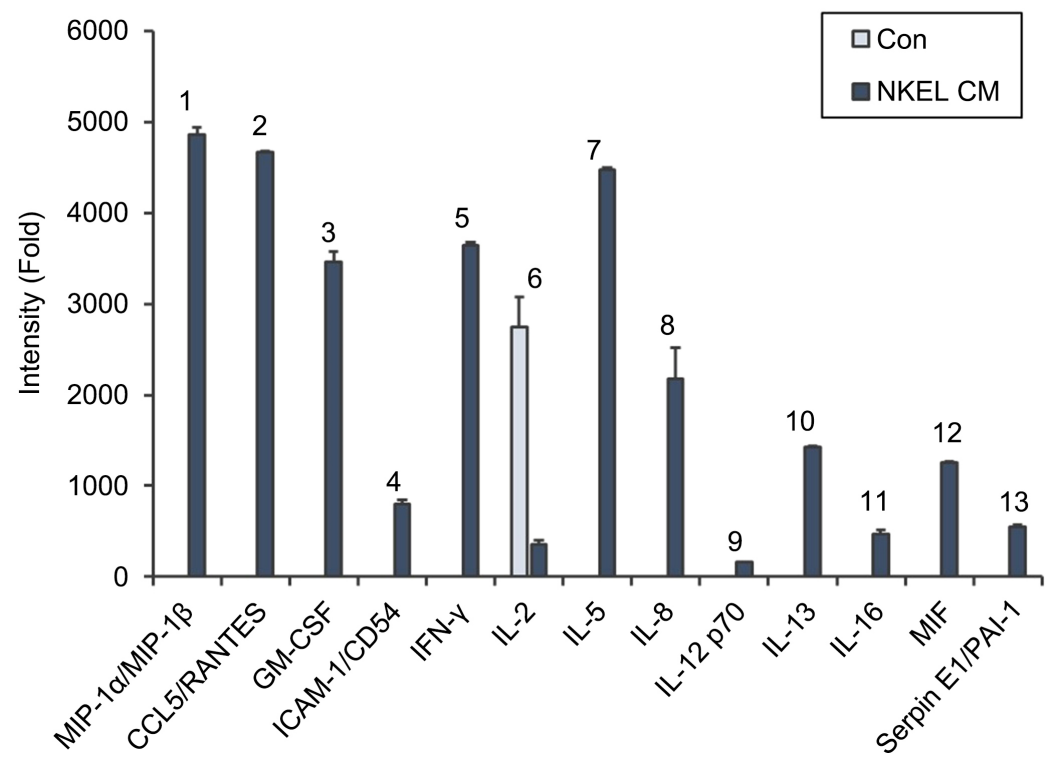

Figure 2. Cytokine array of NKEL CM. NKELs cultured from PBMCs were incubates with KBM502 medium. (a) NKEL CM and media only (Con) cytokine array image was obtained using Davinchi Chemidoc. The Left image is the results of media only (Con), right image is the results of NKEL CM. (b) The intensity of each cytokine was determined by Densitometric analysis using ImageJ. Three independent experiments were performed in triplicate $(\mathrm{n}=3)$.

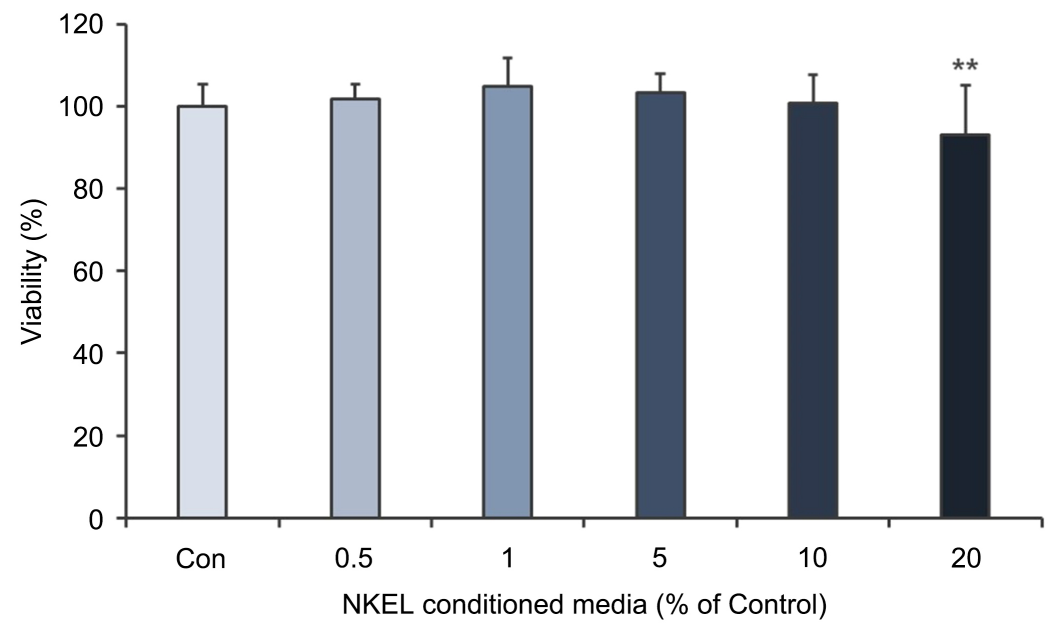

Figure 3. The effect of NKEL CM on the cell proliferation of HaCaT keratinocytes. HaCaT cells were incubated with the indicated concentration of NKEL CM in 1\% FBS DMEM. Proliferation of HaCaT keratinocytes was determined by MTT assay after 24 hours treatment of NK cells CM. The results were expressed as the means and standard deviation. Four independent experiments were performed in quadruplicate $(n=4)$. ${ }^{*} \mathrm{p}<$ 0.01 versus no-treatment control (Con). 


\subsection{The Effect of NKEL CM on the Migration and EMT of HaCaT Keratinocytes}

Cell migration is an essential process in wound healing. To protect the skin barrier, cell migration occurs continuously, and EMT occurs essentially in keratinocytes. EMT is achieved by regulating the expression and activity of various enzymes (i.e. KLKs, MMPs) and transcription factors (i.e. snail, Twist) through signaling pathways. E-cadherin is a cell adherent junction protein as an EMT marker. The E-cadherin of keratinocytes treated with NKEL CM was reduced concentration dependently, which means that NKEL CM allows the motility and migration of cells by affecting the expression of E-cadherin (Figure 4(a)). The $1 \%$ NKEL CM treated group decreased by $0.48 \pm 0.25(\mathrm{p}<0.05)$ times compared to control, and $0.37 \pm 0.37(\mathrm{p}<0.005)$ times in the 5\% NKEL CM treated group, respectively (Figure $4(\mathrm{~b})$ ).

(a)

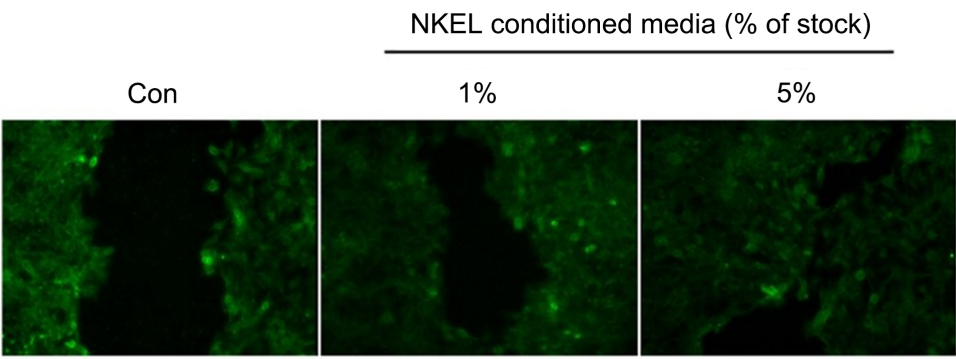

(b)

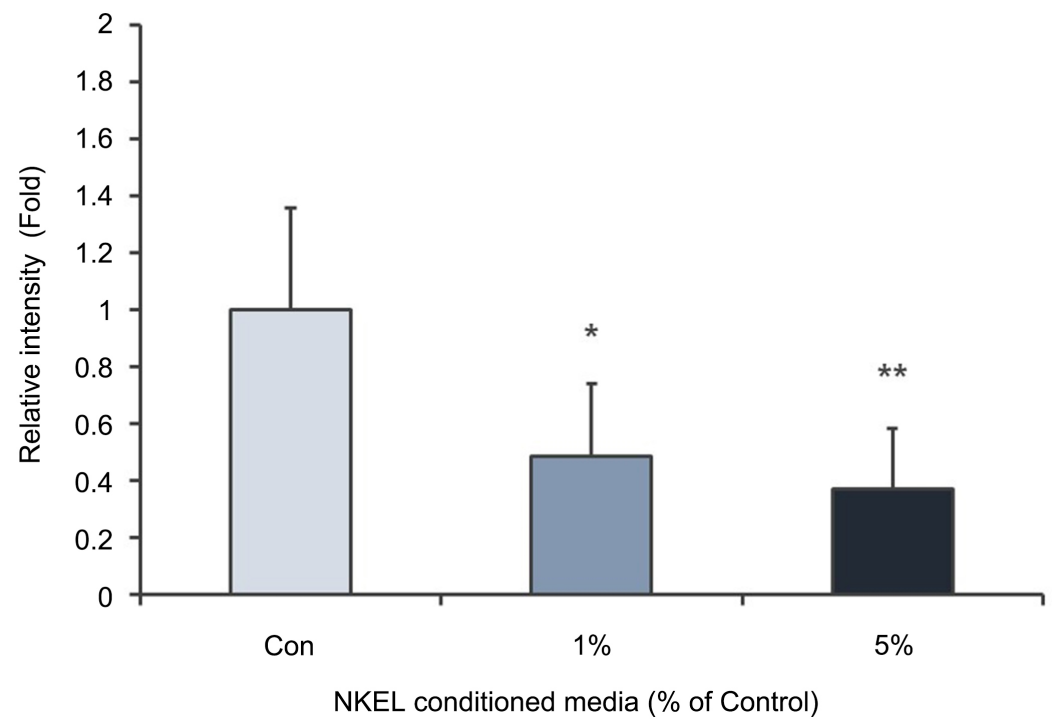

Figure 4. The effect of NKEL CM on down-regulation of E-cadherin in HaCaT keratinocytes. HaCaT keratinocytes were treated at the indicated concentration of NKEL CM and incubated on a cover glass for 24 hours. The cell monolayer was replaced with a fresh medium and scratched. (a) E-cadherin was detected using Immunofluorescence staining. (b) Relative intensity was determined by densitometric analysis using ImageJ software. The results were expressed as the means and standard deviations. Three independent experiments were performed in triplicate $(\mathrm{n}=3) .{ }^{\star} \mathrm{P}<0.05 ;{ }^{*} \mathrm{P}<0.01$ versus no-treatment control (Con). 
A scratch cell migration assay was performed to determine the cell migration effect of NKEL CM on HaCaT keratinocytes. NKEL CM was pretreated on the keratinocyte monolayer, and the reduction rate of the scratch area was calculated as the time zone area. As shown in the results, cell migration was increased as the concentration of NKEL CM escalated (Figure 5(a)). Cell migration rate increased to $139.14 \% \pm 5.32 \%(\mathrm{p}<0.05)$ when the concentration of NKEL CM was $1 \%$, and $187.15 \% \pm 8.63 \%(\mathrm{p}<0.005)$ when it was $5 \%$, respectively (Figure $5(\mathrm{~b})$ ).

Based on these results, it was confirmed that treatment with NKEL CM promotes EMT of HaCaT keratinocytes and cell migration.

\subsection{The Effect of NKEL CM on the Expression of KLK5 and KLK7 in HaCaT Keratinocytes}

In the skin epidermis, keratinocytes form an external barrier and are tightly bound. The stratum corneum formed through keratinization continues to separate from the skin surface. One of the enzymes that play an important role in the

(a)

NKEL conditioned media (\% of stock)

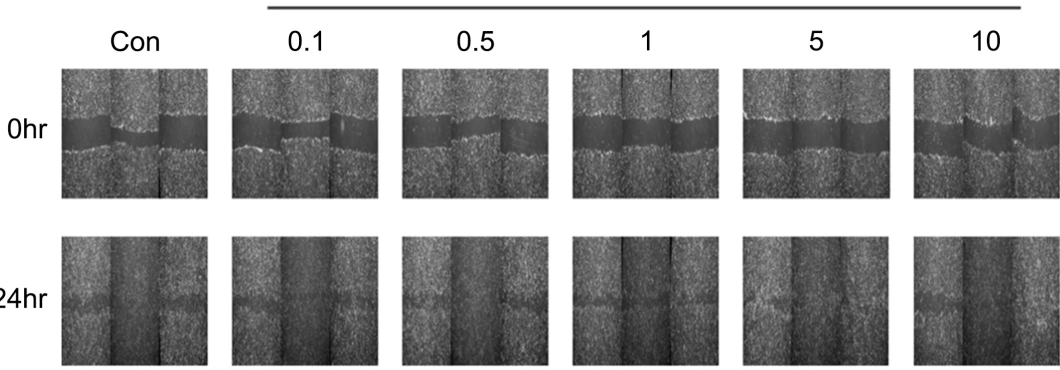

(b)

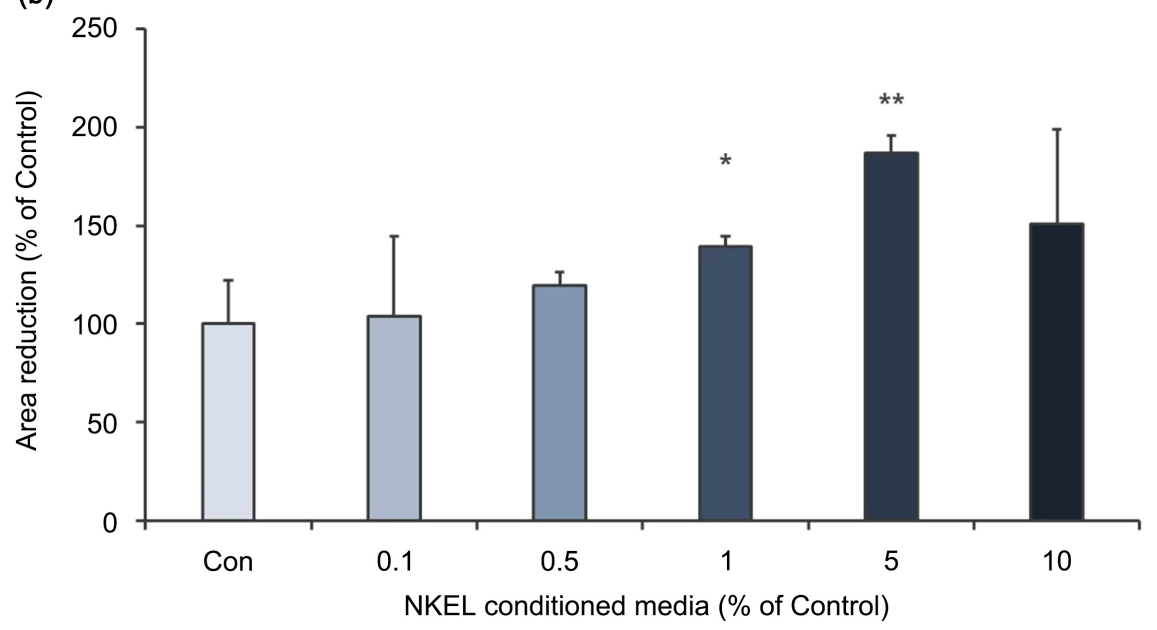

Figure 5. The effect of NKEL CM on the cell migration of HaCaT keratinocytes. The indicated NKEL CM was treated for 24 hours. Confluent HaCaT keratinocytes monolayer about $95 \%-100 \%$ were scratched. And the scratched cells were incubated in a fresh medium without NKEL CM. (a) Microscopic images were obtained immediately on the monolayer of scratched cells after 24 hours. (b) Cell migration was determined by measuring the reduction of the scratched area. The results were expressed as the means and standard deviations. Three independent experiments were performed in triplicate $(n=3)$. ${ }^{\star} \mathrm{P}<0.05 ;{ }^{*} \mathrm{P}<0.01$ versus no-treatment control (Con). 
elimination of the stratum corneum is known as KLKs. KLKs have numerous putative extracellular matrix (ECM) substrates [16]. Therefore, the increased expression of KLKs affects cell migration. Among them, KLK5 and KLK7 show similar proteolytic efficacy, and they take ECM proteins such as fibronectin, integrin, corneodesmosin, E-cadherin, and cell adherent junction proteins as substrates [27].

The expression levels of KLK5 and KLK7 were measured in the NKEL CM treated HaCaT keratinocytes (Figure 6). KLK5 showed a fold value of $1.21 \pm$ $0.04(\mathrm{p}<0.005)$ and $1.47 \pm 0.05(\mathrm{p}<0.001)$ in the NKEL CM $1 \%$ and $5 \%$ treatment group respectively (Figure 6(a)). KLK7 showed a fold value of $1.16 \pm 0.04$ and $1.47 \pm 0.03(\mathrm{p}<0.001)$ in the NKEL CM $1 \%$ and $5 \%$ treatment group respectively (Figure 6(b)). The increased expression of KLKs in NKEL CM treatment groups promotes cell migration and results in a decrease in cell adherent, cell junction proteins such as E-cadherin.

\subsection{The Effect of NKEL CM on the Expression of MMP-1 and MMP-2 in HaCaT Keratinocytes}

MMP-1 and MMP-2 are not only known enzymes that are deeply involved in tissue repair, but are also known to be involved in wrinkle production. The expression levels of MMP-1 and MMP-2 were measured in HaCaT keratinocytes treated with NKEL CM, and NKEL CM seemed to decrease those of MMP-1 and MMP-2 in both media and cell lysates (Figure 7).

For MMP-1, the $5 \%$ media treated group decreased by $0.78 \pm 0.006(\mathrm{p}<0.001)$ times compared to control, and $0.69 \pm 0.02(\mathrm{p}<0.001)$ and $0.78 \pm 0.03$ ( $\mathrm{p}<$ 0.001 ) times in the $1 \%$ and $5 \%$ lysate treated group, respectively (Figure $7(\mathrm{a})$ ).
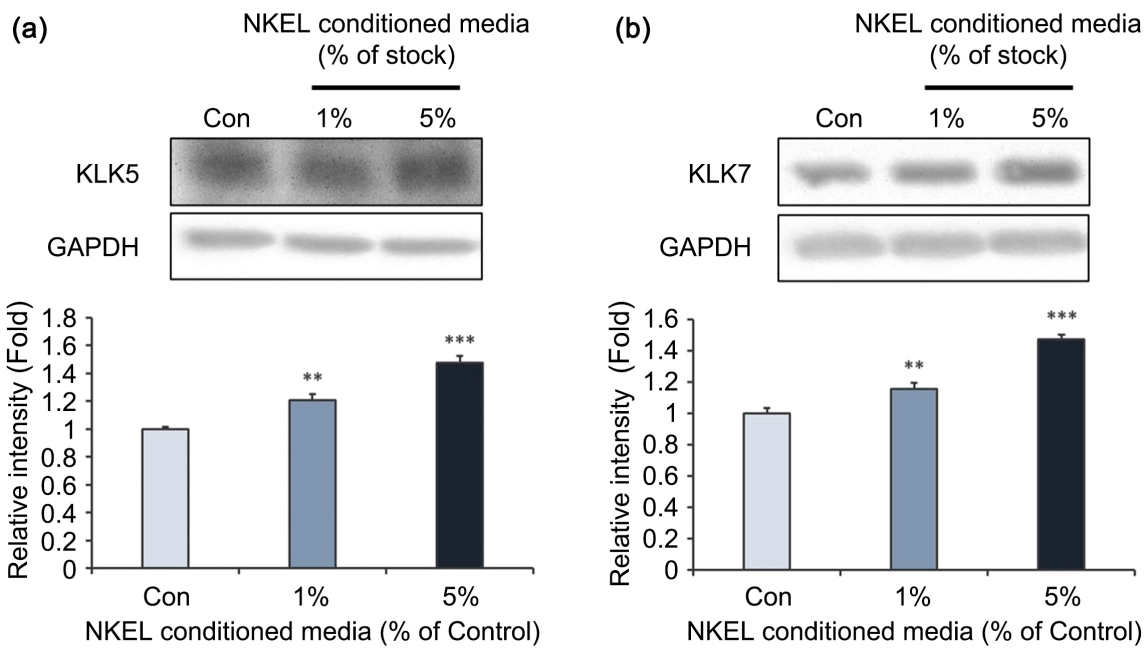

Figure 6. The effect of NKEL CM on the KLK5 and 7 expressions of HaCaT keratinocytes. (a) KLK5, 7 of HaCaT keratinocyte lysate was detected by Western blot analysis. (b) Relative intensity of KLK5, 7 was determined by densitometric analysis. Loading control of KLK5, 7 was GAPDH. Three independent experiments were performed in triplicate ( $\mathrm{n}$ $=3) .{ }^{\star} \mathrm{P}<0.05 ;{ }^{* \star} \mathrm{P}<0.01 ;{ }^{* \star *} \mathrm{P}<0.001$ versus no-treatment control (Con). 

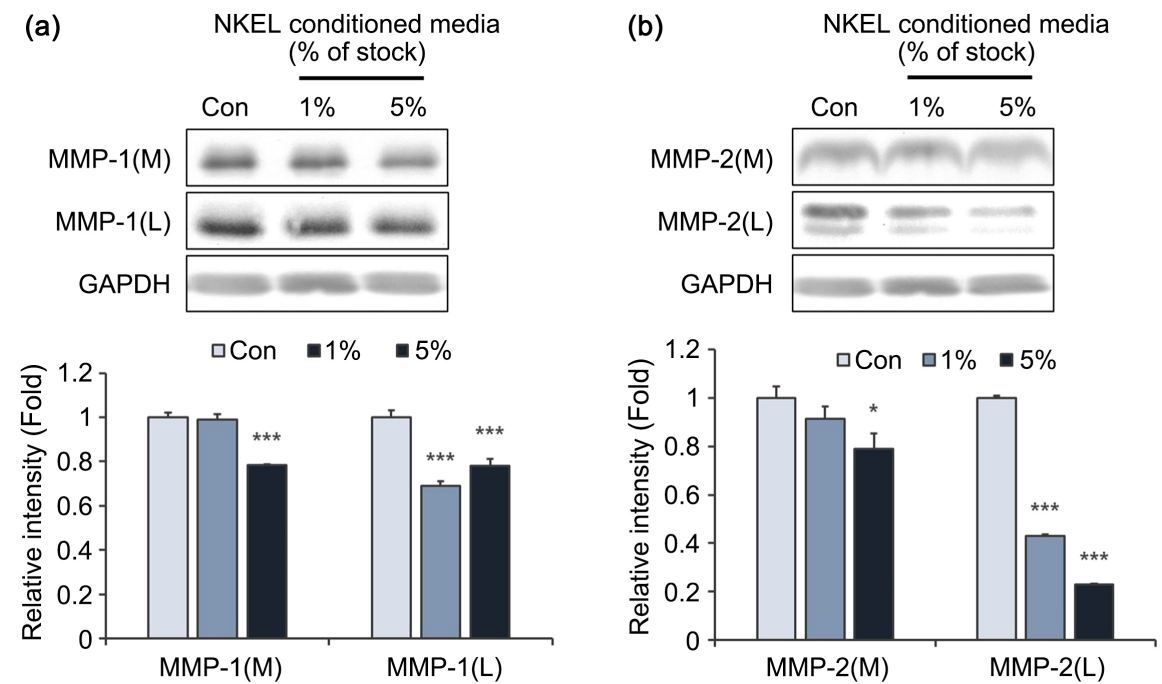

Figure 7. The effect of NKEL CM on the MMP-1 expression and secretion of HaCaT keratinocytes. (a) MMP-1 of whole cell lysate (L) and media (M) was detected by Western blot analysis. (b) Relative intensity of MMP-1 was determined by Densitometric analysis. Loading control for MMP-1 was GAPDH. The results were expressed as the means and standard deviations. Three independent experiments were performed in triplicate $(n=3)$. ${ }^{\star} \mathrm{P}<0.05 ;{ }^{* *} \mathrm{P}<0.001$ versus no-treatment control (Con).

In the case of MMP-2, media showed a fold value of $0.79 \pm 0.06(\mathrm{p}<0.05)$ compared to control in the NKEL CM 5\% treatment group. And in the case of lysate, $0.43 \pm 0.06(\mathrm{p}<0.05)$ compared to control in the NKEL CM $1 \%$ treatment group, and $5 \%$ of treatment groups showed $0.23 \pm 0.04(\mathrm{p}<0.001)$ results (Figure 7(b)). These results show that NKEL CM decreases the expression levels of MMP-1 and MMP-2, and it can be said to mean that it inhibits aging in skin beauty through the anti-wrinkle effect.

\section{Discussion}

The process of aging occurs in all organs of the body, and the skin also ages as it ages. Skin wrinkles are the most important and common symptom of aging skin and are commonly used as a standard for determining the degree of aging [28]. The causes of skin aging are not only endogenous factors that progress over time, but also exogenous factors that can be controlled such as smoking, excessive drinking, malnutrition, and chronic exposure to sunlight. By avoiding the cause of exogenous factors, it is possible to slow skin aging and the formation of skin wrinkles resulting from it, even if it cannot be stopped [29].

NK cell is a type of innate immune cell that not only removes abnormal cells such as cancer cells or virus-infected cells, but also secretes various substances such as cytokine to affect surrounding cells [30] [31]. Recently, as life expectancy has increased, there is a growing concern for health and beauty, and so is interested in the role of immune cells [32]. Although it is difficult to avoid skin damage and aging due to external stimulation, many attempts have been made to slow it down by controlling the function of skin cells [33]. The role of immune 
cells against such skin damage and aging is known, but the role of NKEL CM has not yet been identified. This study shows the results to clarify the role of this NKEL CM on skin. NKEL CM includes various cytokines are contained in NKEL CM as shown in Figure 2. These cytokines are known to be related to wound healing by causing cell migration and EMT, and can play a role in desquamation through the increase of KLKs [34]-[40].

The stratum corneum produced by keratinization continues to fall off from the skin, but in aging skin, it takes longer [41]. Therefore, the deteriorated function of keratinocytes in aging skin may be responsible for thickening of the stratum corneum, causing fine wrinkles and rough skin [42]. One of the enzymes that play an important role in the elimination of the stratum corneum is known as KLK [43]. KLKs are serine proteases with trypsin- or chymotrypsin-like activity and have numerous putative extracellular matrix (ECM) substrates [43]. Several KLKs are expressed in the epidermis of the skin and they are crucially involved in the regulation of skin desquamation [16]. In HaCaT cells treated with NKEL CM, the expression level of KLK increased.

Wound healing can be described simply as an inflammatory reaction, proliferation, and remodeling [44]. During wound healing, cell migration to the wound site is indispensable, and if this step is not done properly, scars are formed, which may adversely affect beauty [45]. HaCaT cells treated with NKEL CM did not significantly affect cell viability as a result of MTT assay, but the migration rate increased. Moreover, the EMT that essentially occurs when cell migration occurs at the wound site was confirmed through E-cadherin, an EMT marker [46] [47]. E-cadherin connects cells by forming a cell-cell adherent junction [48]. When EMT occurs, the expression level of E-cadherin decreases [49] [50]. In our experimental results, it was shown that the intensity of E-cadherin decreased in a concentration-dependent manner in HaCaT cells treated with NKEL CM. These results show that NKEL CM treatment causes EMT of HaCaT cells, allowing keratinocytes to move towards the wound.

When aging occurs, the collagen that acts as a basic component of the extracellular matrix that supports the structure of the skin, hardens or slows down to be synthesized and accelerates decomposition [51] [52] [53]. This change in collagen due to that aging is one of the main causes of wrinkle formation [33]. MMPs are known to be largely involved in wrinkle formation [22]. MMP-1 and MMP-2 mainly take collagen and gelatin as substrates, respectively [54] [55]. Our results showed that the expression levels of MMP-1 and MMP-2 were decreased in $\mathrm{HaCaT}$ cells treated with NKEL CM, which means that NKEL CM can have an anti-wrinkle effect by downregulating MMP-1 and -2 .

We have also shown that NKEL CM contains a variety of cytokines, which increases the cell migration [56]-[62]. Furthermore, it was shown that NKEL CM increased the expression of KLKs and cell migration of HaCaT keratinocytes through EMT.

Overall, our data show that various cytokine mixtures in NKEL CM improved 
exfoliation control and cell migration by regulating the expression of KLKs, and improved wrinkles by reducing the expression of MMP. Considering the effects of NKEL CM such as removing unnecessary dead skin cells, controlling cell migration, activating skin turnover, and inhibiting collagen degradation, this strongly suggests that it is valuable as a cosmetic composition that has an effect on improving skin condition and preventing aging. However, our study has a limitation in that the efficacy of NKEL CM was only verified at the cellular level. Thus, it is considered that the mechanism of action of NKEL CM and efficacy verification through in vivo experiments are necessary for future studies.

\section{Acknowledgements}

This work was supported by the IMMUNISBIO. Co., Ltd.

\section{Conflicts of Interest}

The authors declare no conflicts of interest regarding the publication of this paper.

\section{References}

[1] Global Insight, Inc. (2009) A Study of the European Cosmetics Industry (2007). DG Internal Market, Industry, Entrepreneurship and SMEs, Geneva, Switzerland.

[2] Kumar, S. (2005) Exploratory Analysis of Global Cosmetic Industry: Major Players, Technology and Market Trends. Technovation, 25, 1263-1272. https://doi.org/10.1016/j.technovation.2004.07.003

[3] Dureja, H., Kaushik, D., Gupta, M., Kumar, V. and Lather, V. (2005) Cosmeceuticals: An Emerging Concept. Indian Journal of Pharmacology, 37, 155-159. https://doi.org/10.4103/0253-7613.16211

[4] Sgarbieri, V.C. and Pacheco, M.T.B. (2017) Healthy Human Aging: Intrinsic and Environmental Factors. Brazilian Journal of Food Technology, 20, e2017007. https://doi.org/10.1590/1981-6723.00717

[5] Kabashima, K., Honda, T., Ginhoux, F. and Egawa, G. (2019) The Immunological Anatomy of the Skin. Nature Reviews Immunology, 19, 19-30. https://doi.org/10.1038/s41577-018-0084-5

[6] Verdier-Sévrain, S. and Bonté, F. (2007) Skin Hydration: A Review on Its Molecular Mechanisms. Journal of Cosmetic Dermatology, 6, 75-82. https://doi.org/10.1111/j.1473-2165.2007.00300.x

[7] Nafisi, S. and Maibach, H.I. (2018) Chapter 3-Skin Penetration of Nanoparticles. In: Emerging Nanotechnologies in Immunology, Elsevier, 47-88. https://doi.org/10.1016/B978-0-323-40016-9.00003-8

[8] Del Rosso, J.Q. and Levin, J. (2011) The Clinical Relevance of Maintaining the Functional Integrity of the Stratum Corneum in Both Healthy and Disease-Affected Skin. The Journal of Clinical and Aesthetic Dermatology, 4, 22-42.

[9] Amarya, S., Singh, K. and Sabharwal, M. (2018) Chapter 1-Ageing Process and Physiological Changes. In: D’Onofrio, G., Greco, A. and Sancarlo, D., Eds., Gerontology, IntechOpen, London, UK, 3-24. https://doi.org/10.5772/intechopen.76249

[10] Walters, K.A. (2002) Dermatological and Transdermal Formulations. 1st Edition, CRC Press, Boca Raton. 
https://www.taylorfrancis.com/books/edit/10.1201/9780824743239/dermatological-t ransdermal-formulations-kenneth-walters

[11] Ramos-e-Silva, M. and da Silva Carneiro, S.C. (2007) Elderly Skin and Its Rejuvenation: Products and Procedures for the Aging Skin. Journal of Cosmetic Dermatology, 6, 40-50. https://doi.org/10.1111/j.1473-2165.2007.00289.x

[12] Kontos, C.K. and Scorilas, A. (2012) Kallikrein-Related Peptidases (KLKs): A Gene Family of Novel Cancer Biomarkers. Clinical Chemistry and Laboratory Medicine, 50, 1877-1891. https://doi.org/10.1515/cclm-2012-0247

[13] Prassas, I., Eissa, A., Poda, G. and Diamandis, E.P. (2015) Unleashing the Therapeutic Potential of Human Kallikrein-Related Serine Proteases. Nature Reviews Drug Discovery, 14, 183-202. https://doi.org/10.1038/nrd4534

[14] Kalinska, M., Meyer-Hoffert, U., Kantyka, T. and Potempa, J. (2016) Kallikreins-The Melting Pot of Activity and Function. Biochimie, 122, 270-282.

https://doi.org/10.1016/j.biochi.2015.09.023

[15] Miyai, M., Matsumoto, Y., Yamanishi, H., Yamamoto-Tanaka, M., Tsuboi, R. and Hibino, T. (2014) Keratinocyte-Specific Mesotrypsin Contributes to the Desquamation Process via Kallikrein Activation and LEKTI Degradation. Journal of Investigative Dermatology, 134, 1665-1674. https://doi.org/10.1038/jid.2014.3

[16] Nauroy, P. and Nyström, A. (2019) Kallikreins: Essentialepidermal Messengers for Regulation of the Skin Microenvironment during Homeostasis, Repair and Disease. Matrix Biology Plus, 6-7, Article ID: 100019.

https://doi.org/10.1016/j.mbplus.2019.100019

[17] Rodríguez, D., Morrison, C.J., Overall, C.M., Rodríguez, D., Morrison, C.J. and Overall, C.M. (2010) Matrix Metalloproteinases: What Do They Not Do? New Substrates and Biological Roles Identified by Murine Models and Proteomics. Biochimica et Biophysica Acta, 1803, 39-54. https://doi.org/10.1016/j.bbamcr.2009.09.015

[18] Zakiyanov, O., Kalousová, M., Zima, T. and Tesař, V. (2019) Matrix Metalloproteinases in Renal Diseases: A Critical Appraisal. Kidney and Blood Pressure Research, 44, 298-330. https://doi.org/10.1159/000499876

[19] Freitas-Rodríguez, S., Folgueras, A.R. and López-Otín, C. (2017) The Role of Matrix Metalloproteinases in Aging: Tissue Remodeling and Beyond. Biochimica et Biophysica Acta, 1864, 2015-2025. https://doi.org/10.1016/j.bbamcr.2017.05.007

[20] Tokuhara, C.K., Santesso, M.R., de Oliveira, G.S.N., da Silva Ventura, T.M., Doyama, J.T., Zambuzzi, W.F. and de Oliveira, R.C. (2019) Updating the Role of Matrix Metalloproteinases in Mineralized Tissue and Related Diseases. Journal of Applied Oral Science, 27, e20180596. https://doi.org/10.1590/1678-7757-2018-0596

[21] Cole, M.A., Quan, T., Voorhees, J.J. and Fisher, G.J. (2018) Extracellular Matrix Regulation of Fibroblast Function: Redefining Our Perspective on Skin Aging. Journal of Cell Communication and Signaling, 12, 35-43. https://doi.org/10.1007/s12079-018-0459-1

[22] Pittayapruek, P., Meephansan, J., Prapapan, O., Komine, M. and Ohtsuki, M. (2016) Role of Matrix Metalloproteinases in Photoaging and Photocarcinogenesis. International Journal of Molecular Sciences, 17, 868. https://doi.org/10.3390/ijms17060868

[23] Vivier, E., Raulet, D.H., Moretta, A., Caligiuri, M.A., Zitvogel, L., Lanier, L.L., Yokoyama, W.M. and Ugolini, S. (2011) Innate or Adaptive Immunity? The Example of Natural Killer Cells. Science, 331, 44-49. https://doi.org/10.1126/science.1198687

[24] Zucchini, N., Crozat, K., Baranek, T., Robbins, S.H., Altfeld, M. and Dalod, M. (2008) Natural Killer Cells in Immunodefense against Infective Agents. Expert Re- 
view of Anti-infective Therapy, 6, 867-885. https://doi.org/10.1586/14787210.6.6.867

[25] Almishri, W., Santodomingo-Garzon, T., Le, T., Stack, D., Mody, C.H. and Swain, M.G. (2016) TNFa Augments Cytokine-Induced NK Cell IFN $\gamma$ Production through TNFR2. Journal of Innate Immunity, 8, 617-629. https://doi.org/10.1159/000448077

[26] Justus, C.R., Leffler, N., Ruiz-Echevarria, M. and Yang, L.V. (2014) In Vitro Cell Migration and Invasion Assays. Journal of Visualized Experiments, 88, e51046. https://doi.org/10.3791/51046

[27] Komatsu, N., Takata, M., Otsuki, N., Toyama, T., Ohka, R., Takehara, K. and Saijoh, K. (2003) Expression and Localization of Tissue Kallikrein mRNAs in Human Epidermis and Appendages. Journal of Investigative Dermatology, 121, 542-549. https://doi.org/10.1046/j.1523-1747.2003.12363.x

[28] Trojahn, C., Dobos, G., Lichterfeld, A., Blume-Peytavi, U. and Kottner, J. (2015) Characterizing Facial Skin Ageing in Humans: Disentangling Extrinsic from Intrinsic Biological Phenomena. BioMed Research International, 2015, Article ID: 318586. https://doi.org/10.1155/2015/318586

[29] Krutmann, J., Bouloc, A., Sore, G., Bernard, B.A. and Passeron, T. (2017) The Skin Aging Exposome. Journal of Dermatological Science, 85, 152-161. https://doi.org/10.1016/j.jdermsci.2016.09.015

[30] Wu, S.-Y., Fu, T., Jiang, Y.-Z. and Shao, Z.-M. (2020) Natural Killer Cells in Cancer Biology and Therapy. Molecular Cancer, 19, Article No. 120. https://doi.org/10.1186/s12943-020-01238-X

[31] van Erp, E.A., van Kampen, M.R., van Kasteren, P.B. and de Wit, J. (2019) Viral Infection of Human Natural Killer Cells. Viruses, 11, 243. https://doi.org/10.3390/v11030243

[32] Brown, G.C. (2015) Living Too Long. EMBO Reports, 16, 137-141. https://doi.org/10.15252/embr.201439518

[33] Ganceviciene, R., Liakou, A.I., Theodoridis, A., Makrantonaki, E. and Zouboulis, C.C. (2012) Skin Anti-Aging Strategies. Dermato-Endocrinology, 4, 308-319. https://doi.org/10.4161/derm.22804

[34] Low, Q.E.H., Drugea, I.A., Duffner, L.A., Quinn, D.G., Cook, D.N., Rollins, B.J., Kovacs, E.J. and DiPietro, L.A. (2001) Wound Healing in MIP-1 $1 \alpha^{-1-}$ and MCP-1 Mice. American Journal of Pathology, 159, 457-463. https://doi.org/10.1016/S0002-9440(10)61717-8

[35] Michopoulou, A. and Roussselle, P. (2015) How Do Epidermal Matrix Metalloproteinases Support Re-Epithelialization during Skin Healing? European Journal of Dermatology, 25, 33-42. https://doi.org/10.1684/ejd.2015.2553

[36] Kanno, E., Tanno, H., Masaki, A., Sasaki, A., Sato, N., Goto, M., Shisai, M., Yamaguchi, K., Takagi, N., Shoji, M., Kitai, Y., Sato, K., Kasamatsu, J., Ishii, K., Miyasaka, T., Kawakami, K., Imai, Y., Iwakura, Y., Maruyama, R., Tachi, M. and Kawakami, K. (2019) Defect of Interferon $\gamma$ Leads to Impaired Wound Healing through Prolonged Neutrophilic Inflammatory Response and Enhanced MMP-2 Activation. International Journal of Molecular Sciences, 20, 5657. https://doi.org/10.3390/ijms20225657

[37] Park, S.L., Chung, T.-W., Kim, S., Hwang, B., Kim, J.M., Lee, H.M., Cha, H.-J., Seo, Y., Choe, S.Y., Ha, K.-T., Kim, G., Yun, S.-J., Park, S.-S., Choi, Y.H., Kim, B.K., Kim, W.T., Cha, E.-J., Patterson, C., Kim, W.-J. and Moon, S.-K. (2017) HSP70-1 Is Required for Interleukin-5-Induced Angiogenic Responses through eNOS Pathway. 
Scientific Reports, 7, Article No. 44687. https://doi.org/10.1038/srep44687

[38] Lan, C.-C.E., Wu, C.-S., Huang, S.-M., Wu, I.-H. and Chen, G.-S. (2013) High-Glucose Environment Enhanced Oxidative Stress and Increased Interleukin-8 Secretion from Keratinocytes: New Insights into Impaired Diabetic Wound Healing. Diabetes, 62, 2530-2538. https://doi.org/10.2337/db12-1714

[39] Hänel, K.H., Cornelissen, C., Lüscher, B. and Baron, J.M. (2013) Cytokines and the Skin Barrier. International Journal of Molecular Sciences, 14, 6720-6745. https://doi.org/10.3390/ijms14046720

[40] Zhao, Y., Shimizu, T., Nishihira, J., Koyama, Y., Kushibiki, T., Honda, A., Watanabe, H., Abe, R., Tabata, Y. and Shimizu, H. (2005) Tissue Regeneration Using Macrophage Migration Inhibitory Factor-Impregnated Gelatin Microbeads in $\mathrm{Cu}$ taneous Wounds. American Journal of Pathology, 167, 1519-1529. https://doi.org/10.1016/S0002-9440(10)61238-2

[41] Marks, R. (2004) The Stratum Corneum Barrier: The Final Frontier. The Journal of Nutrition, 134, 2017S-2021S. https://doi.org/10.1093/jn/134.8.2017S

[42] Kim, M. and Park, H.J. (2016) Chapter 3-Molecular Mechanisms of Skin Aging and Rejuvenation. In: Shiomi, N., Ed., Molecular Mechanisms of the Aging Process and Rejuvenation, IntechOpen., London, UK, 57-76. https://doi.org/10.5772/62983

[43] Chen, J.-Q., Liang, B.-H., Li, H.-P., Mo, Z.-Y. and Zhu, H.-L. (2019) Roles of Kallikrein-Related Peptidase in Epidermal Barrier Function and Related Skin Diseases. International Journal of Dermatology and Venereology, 2, 150-155. https://doi.org/10.1097/JD9.0000000000000036

[44] Larouche, J., Sheoran, S., Maruyama, K. and Martino, M.M. (2018) Immune Regulation of Skin Wound Healing: Mechanisms and Novel Therapeutic Targets. Advances in Wound Care, 7, 209-231. https://doi.org/10.1089/wound.2017.0761

[45] Falanga, V. (2005) Wound Healing and Its Impairment in the Diabetic Foot. The Lancet, 366, 1736-1743. https://doi.org/10.1016/S0140-6736(05)67700-8

[46] Stone, R.C., Pastar, I., Ojeh, N., Chen, V., Liu, S., Garzon, K.I. and Tomic-Canic, M. (2016) Epithelial-Mesenchymal Transition in Tissue Repair and Fibrosis. Cell and Tissue Research, 365, 495-506. https://doi.org/10.1007/s00441-016-2464-0

[47] Kuwahara, M., Hatoko, M., Tada, H. and Tanaka, A. (2001) E-Cadherin Expression in Wound Healing of Mouse Skin. Journal of Cutaneous Pathology, 28, 191-199. https://doi.org/10.1034/j.1600-0560.2001.028004191.x

[48] Gloushankova, N.A., Rubtsova, S.N. and Zhitnyak, I.Y. (2017) Cadherin-Mediated Cell-Cell Interactions in Normal and Cancer Cells. Tissue Barriers, 5, e1356900. https://doi.org/10.1080/21688370.2017.1356900

[49] Yilmaz, M. and Christofori, G. (2009) EMT, the Cytoskeleton, and Cancer Cell Invasion. Cancer and Metastasis Reviews, 28, 15-33. https://doi.org/10.1007/s10555-008-9169-0

[50] Lamouille, S., Xu, J. and Derynck, R. (2014) Molecular Mechanisms of Epithelial-Mesenchymal Transition. Nature Reviews Molecular Cell Biology, 15, 178-196. https://doi.org/10.1038/nrm3758

[51] Varani, J., Dame, M.K., Rittie, L., Fligiel, S.E.G., Kang, S., Fisher, G.J. and Voorhees, J.J. (2006) Decreased Collagen Production in Chronologically Aged Skin: Roles of Age-Dependent Alteration in Fibroblast Function and Defective Mechanical Stimulation. American Journal of Pathology, 168, 1861-1868. https://doi.org/10.2353/ajpath.2006.051302

[52] Shoulders, M.D. and Raines, R.T. (2009) Collagen Structure and Stability. Annual 
Review of Biochemistry, 78, 929-958.

https://doi.org/10.1146/annurev.biochem.77.032207.120833

[53] Kular, J.K., Basu, S. and Sharma, R.I. (2014) The Extracellular Matrix: Structure, Composition, Age-Related Differences, Tools for Analysis and Applications for Tissue Engineering. Journal of Tissue Engineering, 5, 2041731414557112. https://doi.org/10.1177/2041731414557112

[54] Van Doren, S.R. (2015) Matrix Metalloproteinase Interactions with Collagen and Elastin. Matrix Biology, 44-46, 224-231. https://doi.org/10.1016/j.matbio.2015.01.005

[55] Hu, X. and Beeton, C. (2010) Detection of Functional Matrix Metalloproteinases by Zymography. Journal of Visualized Experiments, 45, e2445.

https://doi.org/10.3791/2445

[56] Gyulai, R., Hunyadi, J., Kenderessy-Szabó, A., Kemény, L. and Dobozy, A. (1994) Chemotaxis of Freshly Separated and Cultured Human Keratinocytes. Clinical and Experimental Dermatology, 19, 309-311. https://doi.org/10.1111/j.1365-2230.1994.tb01201.x

[57] Takada, K., Komine-Aizawa, S., Hirohata, N., Trinh, Q.D., Nishina, A., Kimura, H. and Hayakawa, S. (2017) Poly I:C Induces Collective Migration of HaCaT Keratinocytes via IL-8. BMC Immunology, 18, Article No. 19.

https://doi.org/10.1186/s12865-017-0202-3

[58] Abe, R., Shimizu, T., Ohkawara, A. and Nishihira, J. (2000) Enhancement of Macrophage Migration Inhibitory Factor (MIF) Expression in Injured Epidermis and Cultured Fibroblasts. Biochimica et Biophysica Acta, 1500, 1-9.

https://doi.org/10.1016/S0925-4439(99)00080-0

[59] Czekay, R.-P., Wilkins-Port, C.E., Higgins, S.P., Freytag, J., Overstreet, J.M., Klein, R.M., Higgins, C.E., Samarakoon, R. and Higgins, P.J. (2011) PAI-1: An Integrator of Cell Signaling and Migration. International Journal of Cell Biology, 2011, Article ID: 562481. https://doi.org/10.1155/2011/562481

[60] Providence, K.M., Higgins, S.P., Mullen, A., Battista, A., Samarakoon, R., Higgins, C.E., Wilkins-Port, C.E. and Higgins, P.J. (2008) SERPINE1 (PAI-1) Is Deposited into Keratinocyte Migration "Trails" and Required for Optimal Monolayer Wound Repair. Archives of Dermatological Research, 300, 303-310. https://doi.org/10.1007/s00403-008-0845-2

[61] Simone, T.M., Longmate, W.M., Law, B.K. and Higgins, P.J. (2015) Targeted Inhibition of PAI-1 Activity Impairs Epithelial Migration and Wound Closure Following Cutaneous Injury. Advances in Wound Care, 4, 321-328. https://doi.org/10.1089/wound.2014.0611

[62] Seeger, M.A. and Paller, A.S. (2015) The Roles of Growth Factors in Keratinocyte Migration. Advances in Wound Care, 4, 213-224.

https://doi.org/10.1089/wound.2014.0540 